\title{
MAKNA BANTEN PARAYASCITA DALAM UPACARA NYAMBUTAN
}

\author{
Oleh : Ni Made Ratini
}

\begin{abstract}
Abstrak
Manusia selalu mendambakan kehidupan sejahtera dan bahagia, suci lahir dan batin, untuk mewujudkannya ia harus menjaga hubungan yang harmonis dengan Sang pencipta (tuhan), dengan sesama manusia dan dengan lingkungan alam sekitarnya. Cara yang ditempuh untuk mewujudkan dengan melaksanakan upacara Yadnya. Upacara Yadnya memerlukan sarana yang disebut Upakara atau Banten. Salah satu upakara/Banten yang digunakan dalam Upacara Nyabutan adalah banten Prayascita.

Banten parayascita dibuat berbentuk bundar dari janur kelapa gading. Unsur-unsur Banten parayascita adalah Sorohan Alit, Penyeneng, Sampaian Padma, Lis Sanjata Panca Dewata, Sampian Nagasari, Bungkak Kelapa Gading, Tirta Parayascita, beras Kuning. Banten Paryascita dipergunakan sebagai pendahuluan dari upacara Nyambutan yang berfungsi sebagai pembersihan dan penyucian leteh, kotoran dari pengaruh dasa mala di lingkungan kegiatan Upacara Nyambutan.

Makna Banten Parayascita dalam Upacara Nyambutan adalah sebagai simbol penyucian rohani / alam pikiran dari pengaruh mala atau kotoran, dengan pikiran yang suci sehingga keselamatan, kesejahteraan dan kebahagiaan hidup tercapai.
\end{abstract}

Kata kunci : Banten Parayascita simbol penyucian rohani.

\section{PENDAHULUAN}

Agama Hindu adalah agama yang mengajarkan ajaran yang bersifat universal. Agama Hindu memberikan kebebasan kepada penganutnya untuk menghayati dan mengamalkan serta merasakan inti sari ajarannya. Dengan sifatnya yang universal itu maka agama Hindu bukanlah agama untuk satu golongan atau satu bangsa saja, melainkan agama Hindu untuk siapa saja yang meyakini dan bersedia untuk melaksanakan ajarannya. Keuniversalan yang dimaksud bahwa agama Hindu berlandaskan pada konsep terciptanya keseimbangan baik lahir maupun batin. Semua ajaran Hindu dijiwai oleh ajaran Weda, walaupun dalam bentuk pelaksanaannya berbeda-beda di berbagai tempat. Keberagaman tersebut merupakan hal 
sangat bernilai bagi umat Hindu karena semua bentuk acara, ritual, etika dipengaruhi oleh budaya setempat di mana Hindu itu tumbuh dan berkembang. Semangat ajaran Weda laksana sumber air yang mengalir terus melalui sungai yang panjang sepanjang abad, melalui daerah-daerah yang luas. Karena lama dan luasnya daerah yang dilalui sehingga wajahnya dapat berubah sesuai daerah yang dilalui namun inti ajarannya tetap sama. Demikian juga dengan kepercayaan kepada Tuhan di setiap daerah selalu mengacu pada tradisi budaya setempat. Dengan adanya budaya, tradisi yang berbeda-beda merupakan keunikan tersendiri bagi umat Hindu yang tidak ada dijumpai pada agama lain. Hal ini merupakan kekayaan yang sangat bernilai bagi umat Hindu. Oleh karena itu umat Hindu perlu bangga dengan adanya beragam budaya, tradisi, upacara yang berbeda, dengan demikian umat Hindu merasa sangat dekat dengan Tuhan, dengan sesama dan dengan lingkungan alam Sekitarnya.

Umat Hindu dalam melaksanakan ajaran Agama Hindu dengan didukung oleh tradisi dan budaya setempat serta orientasi pelaksanaannya mengacu kepada tiga kerangka dasar yang meliputi: (1) Tatwa adalah mengisi kecerdasan otak, melatih kemampuan memandang rahasia-rahasia yang dimiliki oleh Tuhan dan rahasia-rahasia yang terdapat dalam diri serta rahasia-rahasia yang dalam alam lingkungan. (2) Etika (susila) adalah menyuguhkan ajaran untuk melatih tingkah laku yang berperan menumbuhkan peningkatan rasa pada setiap pemeluk. (3) Ritual (upacara yadnya) adalah menyuguhkan ajaran rela berkorban yang pada hakekatnya untuk memelihara hidup. Sebab semua yang hidup di dunia ini bermula dari yadnya Tuhan yang telah Menciptakan alam semesta beserta dengan isinya berdasarkan Yadnya seperti yang disebutkan dalam kitab Bagawadgita Bab III. 10 sebagai berikut:

"Sahayajnah Parajah Srishtva,

Paro vacha prajapatih,

Anema prasavishya dhvam,

Esha yo stvashta kamaduk"

Artinya: 
Pada jaman Dahulu kala Prajapati (Tuhan Yang maha Esa) menciptakan manusia dengan yadnya dan bersabda, dengan ini engkau akan mengembang biak dan biarlah ini jadi sapi perahanmu ( S.Pendit 1989: 69).

Jadi yadnya yang bermula dari Tuhan itu patut diteruskan agar kehidupan di dunia ini berlanjut terus dengan saling beryadnya. Ketiga kerangka di atas merupakan landasan bagi umat Hindu untuk mencapai ketenangan dan ketenteraman. Kerangka dasar ini merupakan satu kesatuan yang saling memberikan fungsi atau sistem secara keseluruhan. Seluruh rangkaian upacara dalam agama Hindu pada dasarnya dilandasi oleh susila, sedangkan susila dilandasi oleh tatwa sehingga pelaksanaan upacara tidak terlepas dari tatanan tatwa (Triguna, 1994: 73).

Agama Hindu adalah mewujudkan keseimbangan. Dengan terwujudnya keseimbangan berarti terwujud pula keharmonisan hidup yang didambakan oleh setiap orang di dunia ini. Wujud keseimbangan yang dimaksud adalah terwujudnya keseimbangan antara manusia dengan Tuhannya, antara manusia dengan manusia, antara manusia dengan lingkungan alam sekitarnya. Ketiga faktor tersebut disebut dengan Tri Hita Karana artinya tiga faktor yang menyebabkan suatu keharmonisan dan kebahagiaan yaitu faktor Tuhan, manusia dan lingkungan. Untuk mewujudkan keharmonisan tersebut umat Hindu Khususnya Umat Hindu Etnis Bali melaksanakan “Upacara nyambutan” (Upacara Manusa Yadnya) menggunakan salah satu sarana / Upakara Banten Parayascita. Upacara Nyambutan adalah suatu upacara yang dilakukan oleh Masyarakat Hindu. Upacara Nyambutan termasuk upacara manusa yadnya yang dilaksanakan ketika bayi berumur tiga bulan Wuku atau 105 hari, Tujuan upacara ini adalah momohon kepada Tuhan untuk menyucikan jiwa dan raga si bayi sekaligus mengesahkan nama si bayi. proses upacara diawali dengan pembersihan, penyucian dilanjutkan dengan upacara mengelilingi lesung, upacara si bayi pertama kali menginjakkan kaki di tanah. Upacara nyambutan memerlukan sarana dan prasaran berupa banten/ sesajen yang disebut dengan Upakara. 
Salah satu Upakara yang digunakan dalam Upacara Nyambuatan berupa banten Prayascita yang memiliki bentuk, fungsi dan makna yang sangat penting. Banten Parayascita digunakan bersamaan dengan Banten Byakala dan durmenggala untuk mengawali upacara sebagai pembersihan Jasmani dan dan rohani.

\section{PEMBAHASAN}

1. Upacara Nyambutan

Upacara Nyambutan disebut juga upacara Nelu Bulanin. Upacara Nyambutan dilaksanakan saat bayi berumur 105 hari (tiga bulan wuku). Upacara ini berfungsi untuk menyambut dan menstanakan Atman si bayi di dalam raga sariranya. ini bersifat ritual formal yang mengandung makna sakral. Upacara ini mengandung nilai untuk menumbuhkan kesadaran Atman pada umat manusia bahwa badan manusia ada jasmani dan Rohani. Dalam praktiknya umat Hindu Etnis Bali yang berkaitan dengan membersihkan Jasmani dan rohani tidak bisa lepas dengan menggunakan sarana banten sebagai wujud korban dalam beryadnya, hal ini bersifat spiritual. Pada upacara Nyambutan memerlukan beberapa jenis Banten seperti Banten Byakala, Parayascita, penyambutan, ayaban, pulogembal dan lain-lain sesuai tingkatan besar kecilnya upacara. Namun pada tulisan ini khusus membahas tentang makna Banten Parayascita dengan unsurunsurnya.

2. Pengertian Upakara Banten Parayascita

Upakara atau Banten merupakan salah satu alat atau sarana dalam pelaksanaan upacara bagi mereka yang menempuh jalan bhakti, karena manusia memiliki kemampuan yang sangat terbatas dalam menghubungkan dirinya dengan Ida Shang Hyang Widhi Wasa. Di dalam Catur Marga Yoga, Upakara tersebut diwujudkan melalui Karma Marga Yoga yang artinya jalan bekerja atau berbuat, karena upacara menjadi bagian integral dari Umat Hindu yang diungkapkan melalui pelaksanaan upacara yang dilengkapi dengan upakara atau banten sebagai bentuk rasa sujud bhakti 
permohonan maaf serta tuntunan keselamatan yang ditujukan kepada Ida Shang Hyang Widhi Wasa (Arwati, 2005: 1).

Banten adalah bahasa simbol yang sakral menurut pandangan Hindu. sebagai bahasa simbol maka Banten sebgai media untuk menvisualisasikan ajaran-ajaran Hindu. sebagai media untuk menyampaikan Sradha dan Bhakti pada kemahakuasaan Hyang Widhi. Banten sebagai satu bentuk budaya sakral keagamaan Hindu yang berwujud lokal, namun di dalamnya terdapat nilai-nilai universal. Sesuai pendapat Sudharta, 2003; 64 landasan konsepsinya universal namun aplikasinya haruslah menurut kondisi kontekstual yaitu: (Iksa, Sakti, Desa, kala) yang penting tidak bertentangan dengan Tattwa. Tatwa adalah hakikat kebenaran Weda.

Prayascita berasal dari bahasa Sansekerta yaitu dari kata "Prayas yang artinya bahagia dan gembira sedangkan kata "citta" artinya alam pikiran. Pikiran yang suci dan netral disebut Citta. Kalau cita itu ditarik dan dipengaruhi oleh dorongan hawa nafsu maka ia disebut manah. Namun apabila ia dapat membeda-bedakan mana yang baik dan nama yang buruk maka pikiran itu disebut wiweka. Dengan wiweka pikiran itu diarahkan kembali menuju citta. Pikiran yang sempat kotor dapat dikembalikan dengan pemahaman Tatwa Jnana, susila dan Upacara Yadnya. Dalam tradisi umat Hindu etnis Bali salah satu Banten yang dipakai dalam upacara nyambutan untuk mengembalikan alam pikiran yang kotor adalah Banten parayascita. Banten ini biasanya dipergunakan bila seseorang melakukan penglukatan (menghilangkan sebel/ Cuntaka).

3. Bentuk Banten Parayascita

Alasnya menggunakan kulit sesayut berbentuk bundar dari janur di atasnya berturut-turut diisi peras dari janur, daun tabia bun 8 lembar dijahit menjadi satu berbentuk bundar seperti padma, di atasnya diisi nasi yang berbentuk bundar dikelilingi oleh jejahitan yang berbentuk Tri Kono yang di atasnya lima iris telor dadar yang diletakan sedemikian rupa sehingga menunjukan ke lima arah mata angin. Banten ini juga dilengkapi dengan buah-buahan, lauk pauk, jajan dan sampinya nagasari, canang genten, 
canang buratwangi. Satu unit Banten Prayascita dilengkapi dilengkapi dengan unsur-unsur banten yang lain seperti:

a. Banten Penyeneng

b. Banten Sorohan alit (peras kecil, Tulung, Sesayut kecil)

c. Canang Pesucian/ pengesikan

d. Padma

e. Lis Sanjata Panca Dewata menggunalan janur kelapa gading

f. 1 takir beras kuning

g. 1 takir daun dadap diulek

h. 1 buah bungkak kelapa gading yang sudah dikasturi (dibuka dengan bukaan berbentuk segi tiga)

i. Mohon Tirta pengelukatan Kepada Tuhan dipimpin oleh Pandita/ Rohaniwan yang memimpin upacara.

4. Fungsi Banten Parayascita

Dalam Upacara Nyambutan, Banten parayascita menyertai Banten Byakala dan Durmenggala, dapat dipergunakan sebagai pendahuluan dari suatu yadnya. Rohaniwan sebelum menghaturkan upakara didahului dengan penyucian ( ngelukat). Dengan menggunakan sarana Banten byakala, durmenggala dan parayascita yang berfungsi sebagai pembersihan dan penyucian leteh, kotoran dari pengaruh dasa mala di tempat lingkungan kegiatan Upacara Nyambutan. Pembersihan/ penyucian diawali dari sanggar surya, pelinggih-pelinggih yang ada di merajan, tugu karang, rumah, dapur, sumur dan semua upakara/ Banten disucikan dan dilanjutkan pembersihan penyucian terhadap anggota keluarga terutama Ibu - Bapak dan anak yang akan diupacarai Nyambutan.

5. Makna Unsur Banten Parayascita

Banten Parayascita merupakan salah satu sarana yang digunakan pada upacara Nyambutan yang setiap unsurnya memiliki makna masingmasing seperti:

a. Alas dasar dari Banten Parayascita menggunakan sesayut dari janur. Sesayut berasal dari bahasa Sanskerta yaitu dari kata Ayu yang 
artinya hidup yang baik. Kata Ayu ini sudah menjadi warga dalam bahasa Jawa Kuno dan Bahasa Bali. Dalam bahasa Bali Kata Ayu ini menjadi kata Rahayu artinya selamat. Sesayut artinya keaselamatan atau kebahagiaan. Alas seayut berbentuk bulat ini melambangkan bahwa perjuangan untuk mencapai hidup yang sejahtera dan selamat harus dilaksanakan secara bertahap. Bentuk bundar sesayut, nasi bundar dan peras bundar sebagai lambang Windu yaitu sebagai perwujudan simbol Kemahakuasaaan Hyang Widhi yang tidak berawal dan berakhir.

b. Banten Penyeneng pada parayascita

Penyeneng adalah jenis bentuk sampian yang di atasnya diisi tiga konjong diranglai menjadi tiga petak yang dirangkai jadi satu, masing masing petak diisi beras dan benang, Tepung tawar dari daun dadap diisi kunir, tepung beras. Tepung tawar sebagai simbol keseimbangan hidup dan kekuatan Penyeneng ini melambangkan konsep hidup yang seimbang, dinamis, produktif dan kuat. Seperti yang dapat dilihat pada puja mantra penyeneng yang berbunyi: “Om Kaki penyeneng Nini Peneyeneng Kajenenin Dening Brahma, Wisnu, Iswara" Kaki dan Nini penyeneng tiada lain Hyang Widhi sebagai Purusa dan Predana sebagai sumber terjadinya kehidupa. Kata Nyeneng dalam bahasa Bali artinya hidup (Wiana, 2001: 3).

c. Banten Sorohan alit terdiri dari (peras, tulung, sayut)

- Banten Peras sebagai lambang Tri Guna Sakti. Tari Guna adalah Sattwam, Rajas dan Tamas. Kalau ke tiga guna itu berada pada struktur yang benar maka ia akan menjadi kekuatan yang luar biasa membawa orang pada sukses dalam hidupnya. Struktur yang ideal dari Tri Guna ini apabila struktur tersebut didominasi oleh guna Sattwam dapat menguasai guna Rajas dan Tamas maka perjuangan mencapai sukses.

- Banten Tulung adalah berbentuk seperti mangkok kecil tiga buah berisi nasi lauk pauk jajan buah-buahan. Kata tulung dalam bahasa 
Bali artinya tolong menolong. Manusia sebagai makhluk sosial memiliki kemampuan untuk melakukan kerja sama dengan sesamanya untuk mencapai tujuan bersama. Banten tulung sebagai lambang wujud kerja sama saling tolong menolong dengan sesama untuk mencapai hidup yang sejahtera.

- Banten Sayut sebagai simbol perjuangan untuk mencapai Rahayu, selamat dan sukses.

d. Banten Pesucian / Pengeresikan

Banten pesucian / pengeresikan dibuat beralaskan ceper diisi celemek tujuh buah, masing-masing celemek berisi ambuh dari daun kembang sepatu yang diiris, Tepung tawar, kekeosok putih dari tepung beras, kekosok kuning dari tepung beras berwarna kuning minyak wangi, sisig dibuat jajan yang dibakar sampai gosong, dan beras. Banten canang pesucian sebagai simbol pembersihan dan penyucian dari pengaruh negatif.

e. Padma

Padma adalah sejenis jejahitan yang diabuat dari janur kelapa gading berbentuk bundar diisi reringgitan. Padma ini sebagai simbol senjata Dewa Siwa yang dapat menyucikan leteh/ cuntaka.

f. Lis senjata

Lis Senjata yang dibuat dari daun janur Kelapa Gading ini umumnya dibuat dalam bentuk sampian Lis dengan lima macam senjata saja. Misalnya reringgitanya dari yang paling bawah melukiskan senjata Naga Pasa senjatanya Dewa Maha Dewa, terus diatasnya Gada senjatanya Dewa Brahma, berikutnya Padma senjata Dewa Siwa, diatasnya Cakra senjata Dewa Wisnu. Di atas Cakra adalah Bajra senjata Dewa Iswara. Di atas senjata Bajra ada mata dan terus paling diatas menggambarkan rambut. Ini menggambarkan bahwa seluruh sejata kekuatan Dewa itu adalah satu dari Hyang Widhi Wasa. Sejata para Dewa itu lambang kesucian Tuhan yang akan melenyapkan segala kekotoran alam pikiran. Dengan Sampian Lis Senjata inilah kita 
dimotivasi dengan cara ritual agar terus kita memikirkan nama Tuhan. Kalau pikiran selalu diarahkan pada Nama Tuhan dengan kesucianya maka pikiranpun menjadi suci.

g. Bungkak kelapa gading yang dikasturi berbentuk segi tiga yang digunakan airnya diperciki dengan sarana lis senjata panca dewata untuk menyucikan bangunan suci dia area merajan, sarana upacara, sumur, dapur, rumah dan dicipratkan di atas kepala keluarga yang melaksanakan upacara nyambautan (Penyucian buana agung dan Bhuana alit).

h. Tirta parayascita

Tirta parayascita diperoleh dengan memantrai air oleh pandita atau rohaniwan sebagai pemimpin upacara penggunaanya sama dengan air bungkak kelapa gading namun dicipratkan dengan jejahitan padma, sebagai simbol penyucian Bhuwana agung dan buana alit (Putra, $2001 ; 15)$

\section{Makna Banten Parayascita dalam Upacara Nyambutan}

Dalam tradisi Umat Hindu etnis Bali salah satu Banten yang dipakai dalam Upacara Yadnya untuk mengembalikan alam pikiran yang kotor itu adalah Banten Prayascitta. Kalau Banten Byakala yang bermakna sebagai lambang penyucian yang bersifat lahiriah. Sedangkan Banten Prayascitta sebagai lambang penyucian rohaniah. Karena itu Banten Prayascitta ini selalu menyertai Banten Byakala atau Banten Durmangala. Banten Prayascitta ini biasanya dipergunakan setelah Banten Byakala atau Banten Durmengala dihaturkan. Ini berarti penyucian Sakala (lahiriah) terlebih dahulu barulah penyucian Niskala (rohaniah). Seluruh bahan Banten Prayascitta hendaknya sedapat mungkin menggunakan daun kelapa Gading terutama sampian Padma dan Lis Senjata.

Khusus Kelapa Gading disebutkan dalam Lontar Taru Premana sebagai keturunan Dewa Surya yang dibentuk dari sari-sari ilmu Kepanditaan. Ilmu Kepanditaan ini dalam Taru Premana berwujud dalam Kelapa Gading. Karena itu Kelapa Gading dapat dijadikan sarana untuk mengobati berbagai 
macam penyakit. Disamping itu dalam Lontar Taru Premana disebutkan Kelapa Gading memiliki kekuatan magis untuk Ngelukat berbagai kekotoran. Dalam Lontar Taru Premana disebutkan:

Titiyang I kelungah Nyuh Gading Sesarin Sang Pandita, titiyang wenang Anglukat sekancan Leteh, Titiyang pinaka warih Bhatara Surya mumi (Wiana,2001: 172)

Dari uraian Lontar inilah ada keyakinan dikalangan umat Hindu bahwa Kelapa Gading itu memiliki kekuatan magis religius. Kelapa Gading disamping digunakan air buahnya yang muda (dalam bahasa Bali disebut Bungkak) sebagai Tirtha Panglukatan, juga digunakan daunya sebagai Lis Senjata dan sebagai Sampian Padma. Padma ini khusus sebagai lambang senjata Dewa Siwa sebagai pemusnah kekotoran. Lis Senjata yang dibuat dari daun janur Kelapa Gading ini umumnya dibuat dalam bentuk sampian Lis dengan lima macam senjata saja. Misalnya reringgitanya dari yang paling bawah melukiskan senjata Naga Pasa senjatanya Dewa Maha Dewa, terus diatasnya Gada senjatanya Dewa Brahma, berikutnya Padma senjata Dewa Siwa, diatasnya Cakra senjata Dewa Wisnu. Di atas Cakra adalah Bajra senjata Dewa Iswara. Di atas senjata Bajra ada mata dan terus paling diatas menggambarkan rambut. Ini menggambarkan bahwa seluruh sejata kekuatan Dewa itu adalah satu dari Hyang Widhi Wasa.

Seluruh senjata para Dewa itu lambang kesucian Tuhan yang akan melenyapkan segala kekotoran alam pikiran. Dengan Sampian Lis Senjata inilah kita dimotivasi dengan cara ritual agar terus kita memikirkan nama Tuhan. Kalau pikiran selalu diarahkan pada Nama Tuhan dengan kesucianya maka pikiranpun menjadi suci.

Menurut Puja penganter Banten Prayscitta itu ada lima Mala atau kekotoran diri yang dimohonkan dapat hilang dengan Banten Lis itu, yaitu Sarwa Rogha artinya segala macam penyakit, Sarwa Wighna artinya segala halangan, Sarwa Satru yaitu semua musuh, Papa Klesa yaitu lima klesa yang mengotori hidup dan Sarwa Dusta artinya terhindar dari bencana oleh orang-orang jahat. Dusta dalam bahasa Sanskerta artinya orang 
jahat. Demikianlah banten Prayascitta bertujuan sebagai sarana ritual yang sakral untuk melindungi pikiran dari lima kekotoran itu.

\section{Penutup}

Berdasarkan beberapa uraian diatas maka dapat disimpulkan sebagai berikut:

1. Banten Parayascita berbentuk bundar, nasi bundar, laik pauk, jajan buah-buahan, sampaian nagasari, dilengkapi dengan sorohan alit, Pesucian penyeneng, lis senjata panca Dewata, padma, air bungkat kelapa gading, dan tirta. Ditata sedemikian rupa sehingga berbentuk bundar, indah.

2. Fungsi Banten Parayascita dipergunakan sebagai pendahuluan dari suatu yadnya. Rohaniwan sebelum menghaturkan upakara didahului dengan penyucian ( ngelukat). Dengan menggunakan sarana Banten byakala, durmenggala dan parayascita yang berfungsi sebagai pembersihan dan penyucian leteh, kotoran dari pengaruh dasa mala di tempat lingkungan kegiatan Upacara Nyambutan.

3. Makna Banten Parayascita dalam Upacara Nyambutan adalah sebagai simbol menyucikan rohani dari pengaruh Mala atau kotor untuk mencapai keselamatan, kesejahteraan dan kebahagiaan hidup.

\section{DAFTAR PUSTAKA}

Arwati, Sri Ni Made, " Makelem suatu upacara Bhuta Yadnya" penerbit Pemerintah propinsi Bali, 2001.

Muterini, I Gusti Agung Mas, 2001. Panca Yadnya, Bali : Pemda Propinsi Bali Pendit Nyoman S, 1989. Bhagawadgita, Jakarta,Dharma sarati.

Puja,G dan Sudharta tjokorde Rai. 2003. Menawa DharmaSastra (Manu Dharmasastra atau Weda Smrti Compendium Hukum Hindu, Jakarta: Pustaka Mitra Jaya.

Putra,Ny. I Gusti Agung Mas. 2001, Upakara Yadnya, Bali : Pemda Propinsi Bali.

Triguna, Ida Bagus Gde Yudha, 2000. Teori Tentang Simbol, Denpasar : Widya Dharma. 
Wiana I Ketut. 2003, Makna Upacara Yadnya dalam Agama Hindu, Surabaya: Paramita. 